\title{
Automatic Water Level Control System
}

\author{
Asaad Ahmed Mohammedahmed Eltaieb ${ }^{1}$, Zhang Jian Min ${ }^{2}$ \\ Department of Electronic Engineering, Tianjin University of Technology and Education, China - Tianjin
}

Supervisor, Department of Electronic Engineering, Tianjin University of Technology and Education, China - Tianjin

\begin{abstract}
Water scarcity is one of the major problems facing major cities of the world and wastage during transmission has been identified as a major culprit, this is one of the motivations for this research, to deploy computing techniques in creating a barrier to wastage in order to not only provide more financial gains and energy saving, but also help the environment and water cycle which in turn ensures that we save water for our future. In our system used arduino to automate the process of water pumping in a tank and has the ability to detect the level of water in a tank, switch on or off the pump accordingly and display the status on an LCD screen. The system also monitoring the level of water in the sump tank (source tank). If the level inside the sump tank is low, the pump will not be switched $\mathrm{ON}$ and this protects the motor from dry running. A beep sound is generated when the level in the sump tank is low or if there is any fault with the sensors.
\end{abstract}

Keywords: Arduino, water level

\section{Introduction}

In everyday life, there must be some physical elements that need to be controlled in order for them to perform their expected behaviors. A control system therefore can be defined as a device, or set of devices, that manages commands, directs or regulates the behavior of other device or system. Consequently, automatic controlling involves designing a control system to function with minimal or no human interference. Intelligent systems are being used in a wide range of fields including from medical sciences to financial sciences, education, law, and so on.

The monitoring of the water level in a reservoir is important in the applications related to agriculture, flood prevention, and industry, etc.

Almost all aspects of human life have undergone rapid development. This development is supported by the advance of electronics and information technology. The job can be performed on schedule precisely and efficiently by adopting this advance technology.

An achievement in computer technology is used not only in business and industry but has also covers almost all fields, including control system where a computer system can be used to control the hardware in a flexible way. Therefore, computer based control system is become more common in recent development of control system.

Computer-based control system also can be implemented for optimizing water flow management to minimize flood caused by water overflow. Management can be performed based on elevation of water level on the river as an input data and control the sluices along the river stream based on that data.

Automatic water level controller is a series of functions to control the Automatic Water Pump Controller Circuit in a reservoir or water storage. The water level sensor is made with a metal plate mounted on the reservoir or water tank, with a sensor in the short to create the top level and a detection sensor for detecting long again made for the lower level and ground lines connected to the bottom of reservoirs or reservoir.

the project is automatic water level controller through the use of different technologies in its design, development, and implementation. In this project we will use arduino Uno to automate the process of water pumping in over-head tank storage system and has the ability to detect the level of water in a tank, switch on/off the pump accordingly .The water level and other important data are displayed on a 16×2 LCD display. The circuit also monitoring the level of water in the sump tank (source tank).

\section{Objective}

There are some objectives need to be achieved in order to accomplish this project. These objectives will act as a guide and will restrict the system to be implemented for certain situations:

1) To develop water level control system, to control the water level in the tank.

2) To check the level of water in the tank, depending on the water level switches the motor on when the water level goes below a predetermined level or switches the motor off when the tank full.

3) To display the water level and other important data on a $16 \times 2$ LCD.

4) To monitoring the level of water in the sump tank (source tank). If the level inside the sump tank is low, the motor will not be switched on, and a beep sound is generated.

5) Use arduino c language software to write the code.

\section{Project Description}

The aim of this project is to develop prototype of water level control that can be viewed as a part of control system of reservoirs or reservoir.

The circuit diagram of the water level controller using Arduino is shown below. Conductive method is used to measure the level. The sensor assembly consists of four 


\section{International Journal of Science and Research (IJSR) \\ ISSN (Online): 2319-7064}

Index Copernicus Value (2013): 6.14 | Impact Factor (2014): 5.611

aluminum wires arranged at 1/4, 1/2, 3/4 and full levels in the tank. The dry ends of these wires are connected to analog input pins of the Arduino respectively,

A fifth wire is positioned at the bottom of the tank the resistors are pull down resistors. The dry end of this wire is connected to $+5 \mathrm{~V}$ DC. When the water touches a particular probe, electrical connection is established between that probe and the $+5 \mathrm{~V}$ probe because water has slight conductivity. As a result current flows through that probe and this current is converted into a proportional voltage by the pull down resistor. Arduino reads the voltage dropped across each pull down resistor for sensing the level of water in the tank. Same method is used for measuring the level of water in the sump tank. Buzzer and pump unit are connected to the digital output pins of the arduino.

\section{Block Diagram of the System}

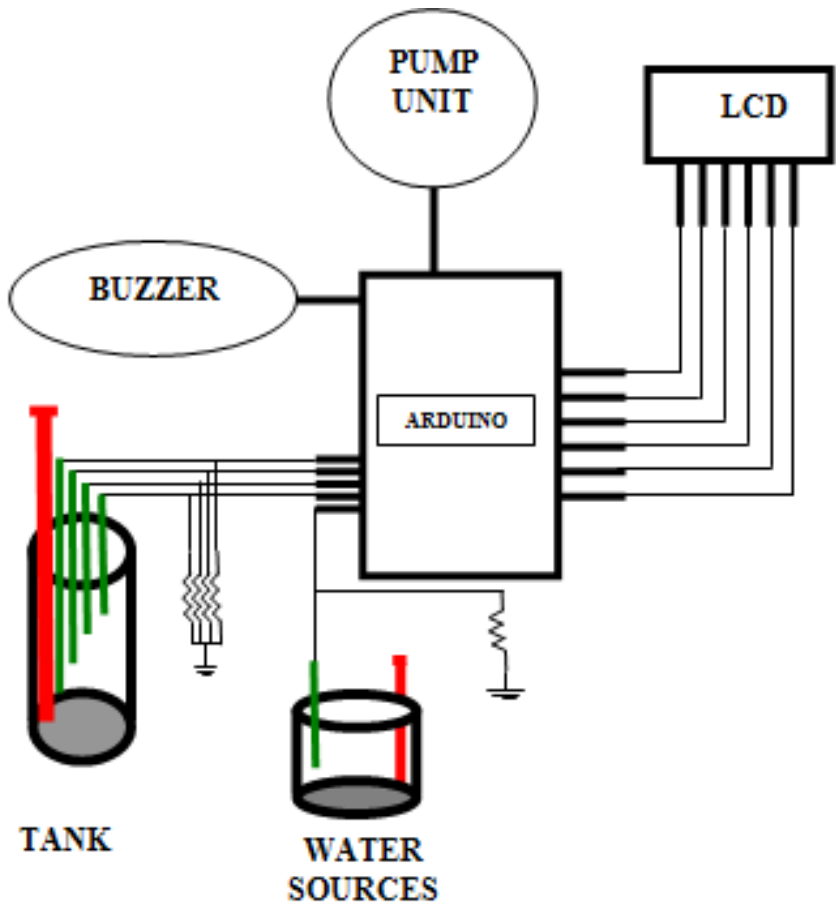

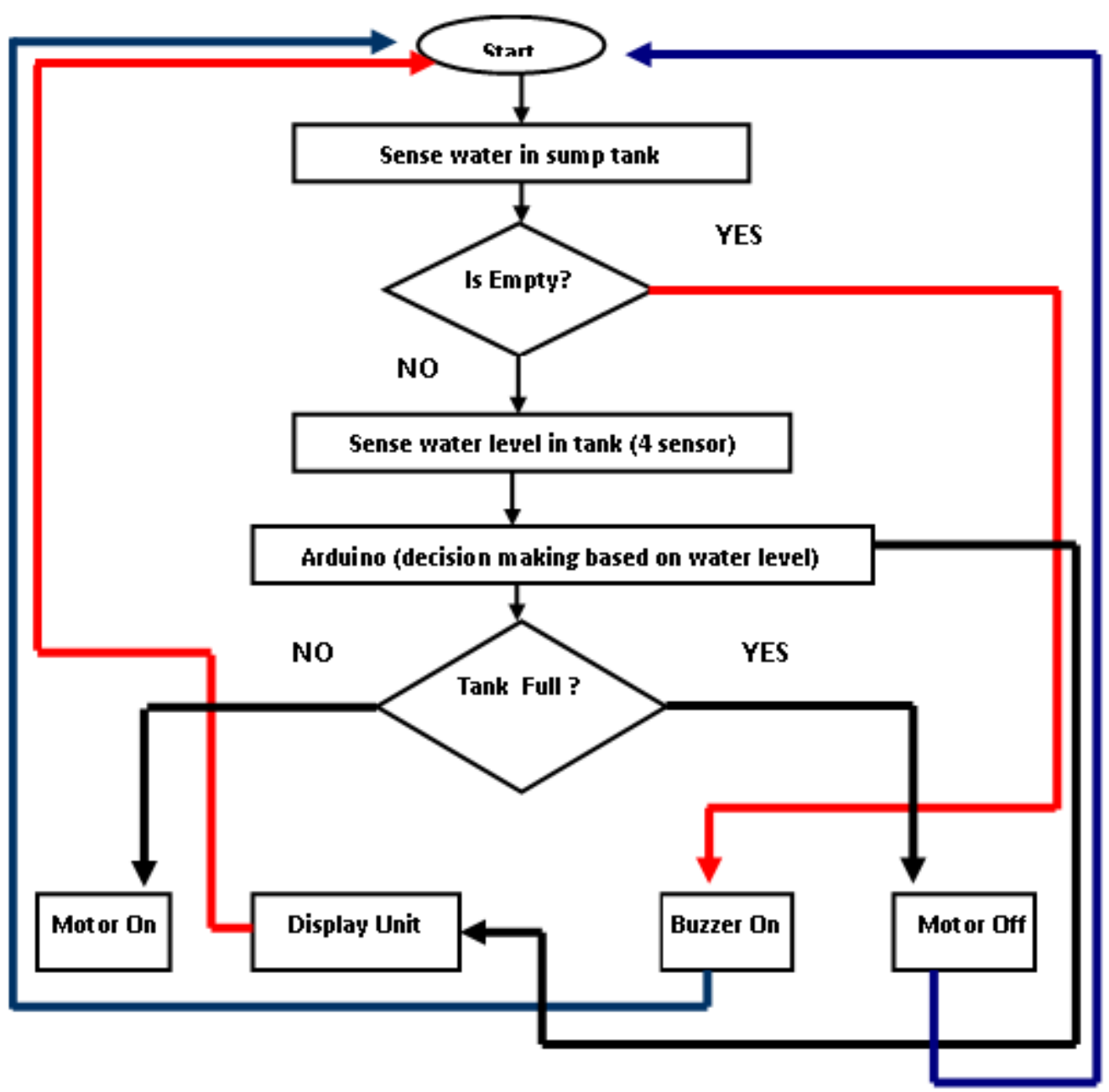

System flowchart

\section{Hardware Design}

The system performs the sensing level and control activities without the manual observation and attention in the site. Being an automatic system unavailing manpower and providing information for long period of time. The automatic water level control system has the following main components.

\section{Volume 4 Issue 12, December 2015}




\section{International Journal of Science and Research (IJSR) \\ ISSN (Online): 2319-7064}

Index Copernicus Value (2013): 6.14 | Impact Factor (2014): 5.611

\section{Sensor Unit}

The sensor assembly consists of four aluminum wires arranged at 1/4, 1/2, 3/4 and full levels in the tank. The dry ends of these wires are connected to analog input pins A1, A2, A3 and A4 of the Arduino respectively. A fifth wire is positioned at the bottom of the tank.

\section{Control Unit}

The basic operation of control unit is the controlling water pump by arduino which is programmed by particular program. Water pump are connected with an output pin of arduino via a relay circuit which is connected with a transistor.

\section{Liquid Crystal Display (LCD)}

LCD is the most common message display device used to display ASCII character. LCDs have become a cheap and easy way to get text display for embedded system. The Common displays are set up as 16 to 20 characters by 1 to 4 lines.

\section{Buzzer}

It is an electronic used to give alarm sound as it is programmed.

\section{SIMULATION}

Using PROTEUS software, now it is possible to draw a complete circuit for a arduino based system and then tests it interactively. With PCB layout the software now also offering automation of both component placement and track routing, getting the design into the computer can often be the most time consuming element of the exercise. And if you use circuit simulation to develop your ideas, you are going to spend even more time working on the schematic. So when we simulate our program which had written in arduino c language, and as we wrote before that we will always show the water level on the LCD and we will turn - on and off- the pump unit according to this value.

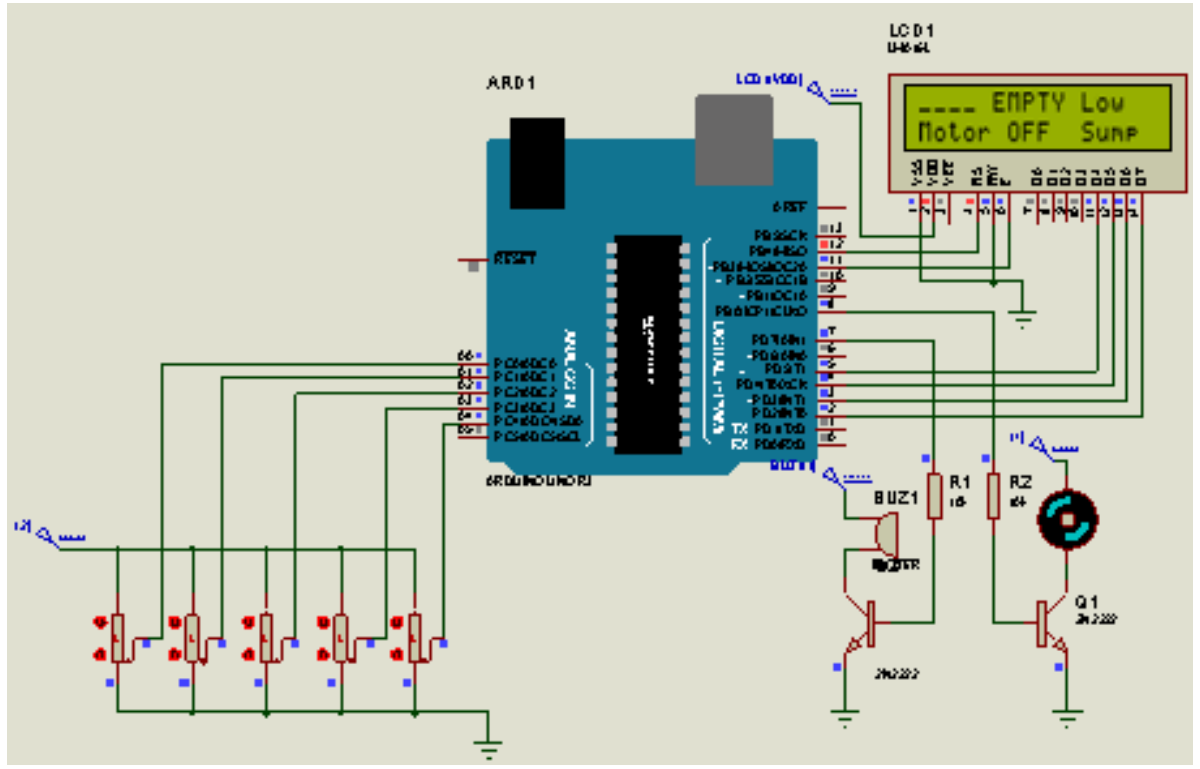

The sump tank is low and reservoir is empty the buzzer generate sound

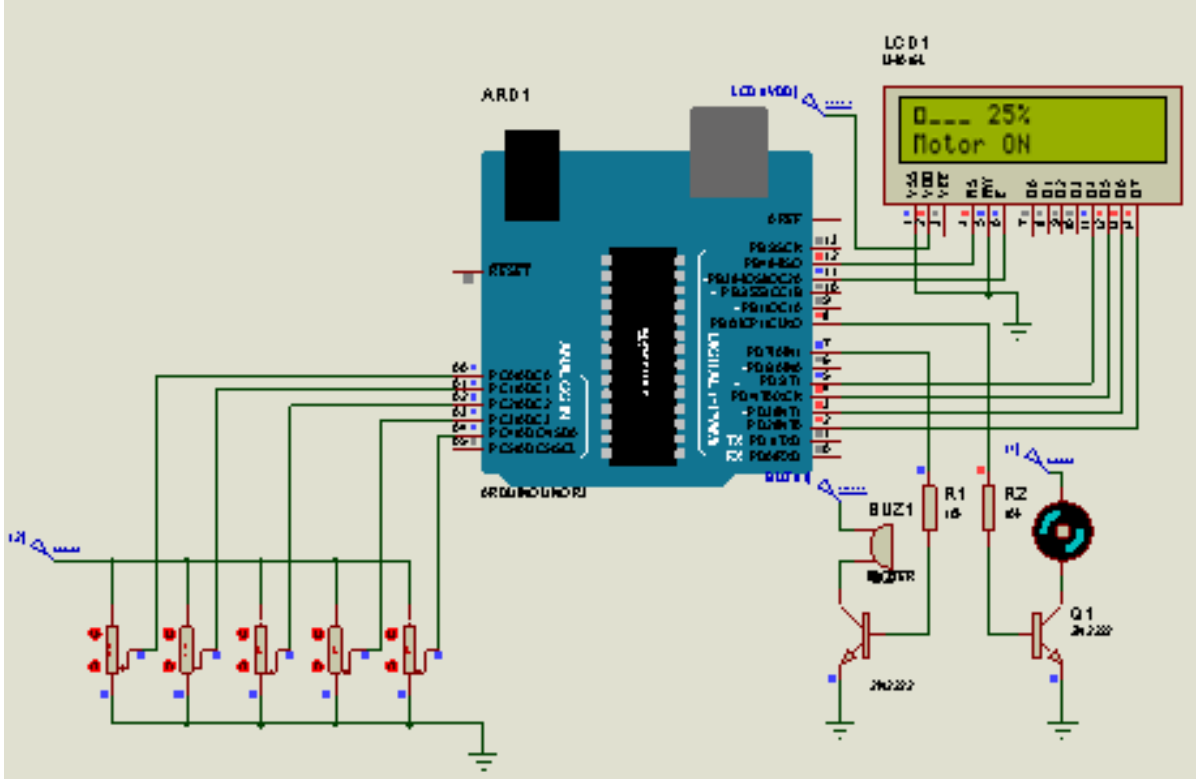

The $25 \%$ level display

Volume 4 Issue 12, December 2015 


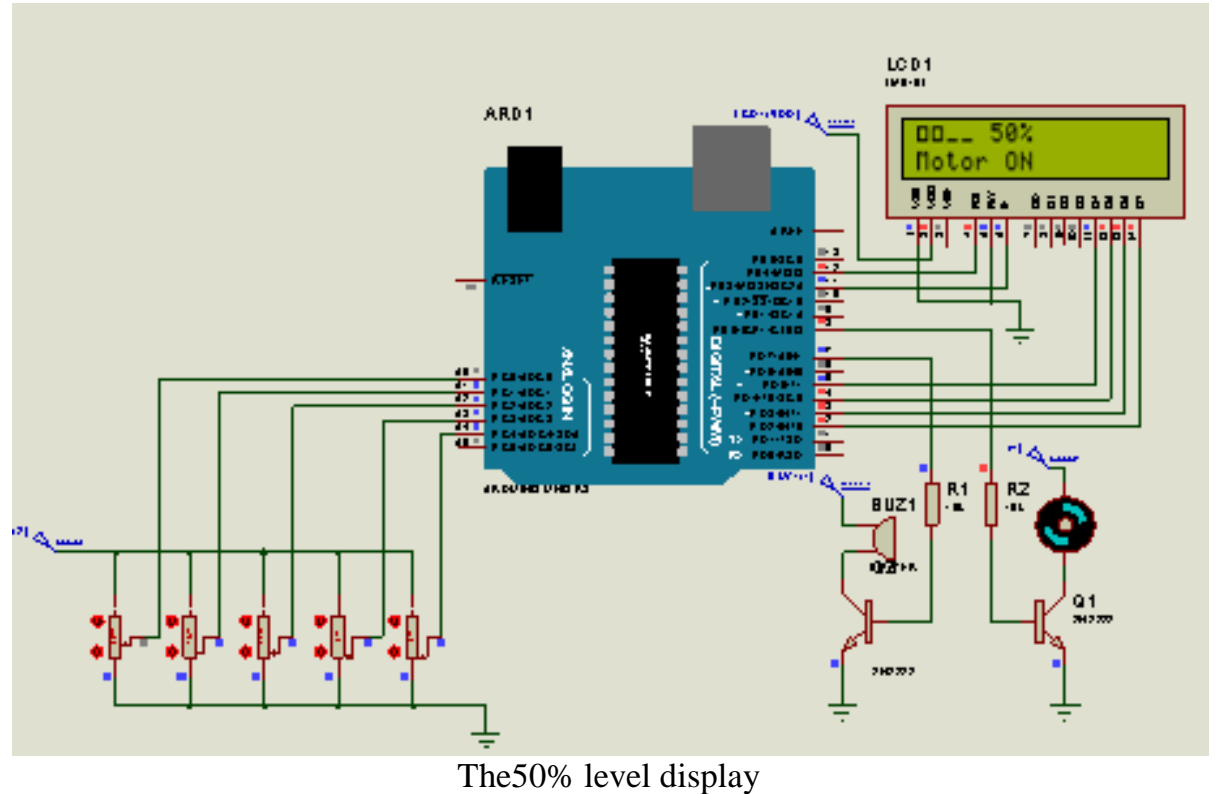

The50\% level display

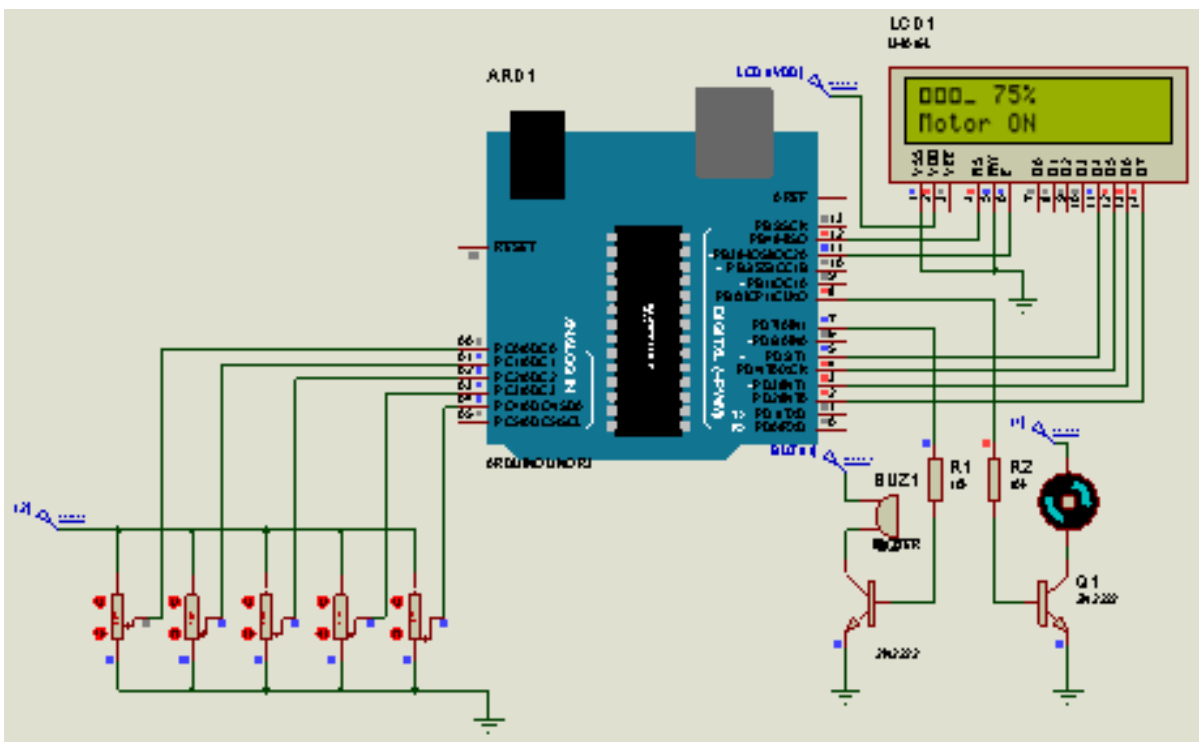

The $75 \%$ level display

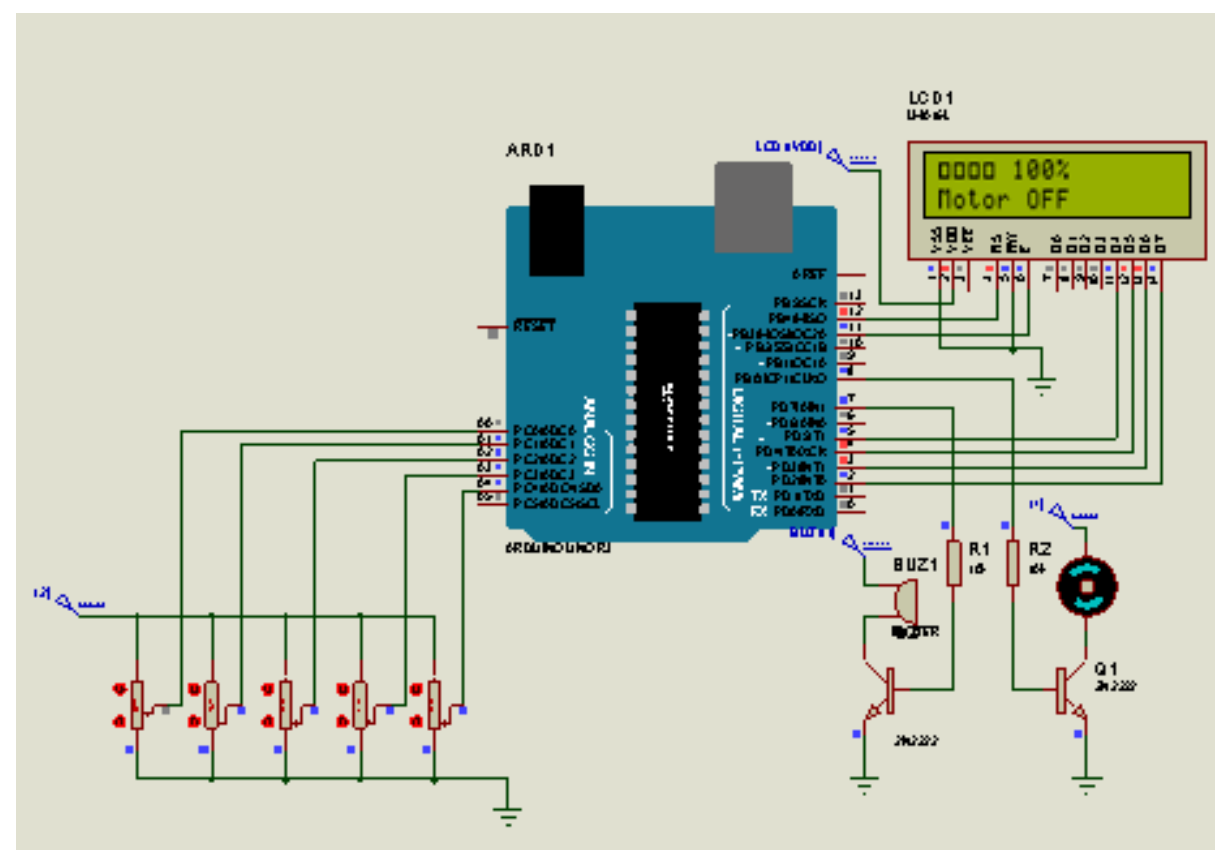

The $100 \%$ level display

Volume 4 Issue 12, December 2015

www.ijsr.net 


\section{International Journal of Science and Research (IJSR) \\ ISSN (Online): 2319-7064}

Index Copernicus Value (2013): 6.14 | Impact Factor (2014): 5.611

\section{Conclusion}

This project has achieved the main objectives. Moreover, this project involved designing and development of automatic water level control system had exposed to the better way of software and hardware architecture that blends together for the interfacing purposes. The system employs the use of advance sensing technology to detect the water level.

\section{References}

[1] http://www.arduino.cc/en/Main/ArduinoBoardUno

[2] http://en.wikipedia.org/wiki

[3] http://www.engineersgarage.com.

[4] http://www.micropik.com

[5] http://www.academia.edu/7305282/Design_and_Implem entation

of_Mirocontroller_Based_Process_Line_Liquid_Level_ Control_and_Monitoring_System_for_Industries

[6] http://www.datasheetdirect.com

[7] http://electrofriend.com

[8] http://www.worldbank.org 